\title{
Chagas disease: pushing through the pipeline
}

\section{Forty years after the first drugs were introduced, what are the prospects for new ones?}

n April 2007, a 44-year-old woman came to a hospital in Barcelona, Spain, suffering from systemic lupus erythematosus - in which the immune system attacks the body's own tissues, including the kidneys ${ }^{1}$. The treatment would have been straightforward, except that she had a second problem: infection with Trypanosoma cruzi, which is the parasite that causes Chagas disease. The woman was originally from Northern Argentina, where Chagas disease is endemic, and had been infected for 20 years without experiencing any long-term complications. Her doctor, María-Jesús Pinazo, suspected that the parasite was lurking deep within the body tissues, held in check by the immune system. Therein lay the challenge: treating the lupus with immune-suppressing drugs might 'release the brakes' on T. cruzi, causing reactivation and potentially life-threatening inflammation of the heart or brain.

Sure enough, after 1 month of treatment the parasite was back in circulation, and addition of benznidazole, the drug most frequently used to treat Chagas disease, failed to suppress it. Nevertheless, this potential 'no-win situation' in fact became a turning point and an important proof-of-principle for a new treatment for Chagas disease, as Pinazo gave the patient posaconazole (Schering Plough, now Merck \& Co., Inc.), which is an anti-fungal medication. Pinazo had read research by Julio Urbina and his collaborators showing that posaconazole is effective against T. cruzi, including strains resistant to benznidazole, in cell culture and animal models. Pinazo persuaded her hospital to obtain the drug on a compassionate basis: "We thought that would be the best chance for the patient." Fortunately, 3 years later, real-time PCR remains negative and there is no evidence of treatment failure - the patient is apparently free from parasitic infection.

This case was, in effect, a natural experiment that would have otherwise been unethical suppressing the immune system and reactivating the parasite. "If the drug can cure in this [compromised] condition it should be possible to cure patients who are immune-competent," says Urbina, who was formerly at the Instituto Venezolano de Investigaciones Cientificas in Caracas, Venezuela, and is now a consultant based in the United States. Posaconazole, he believes, can penetrate infected tissues.

As a result of animal studies and encouraged by the Barcelona case, posaconazole is poised to go into a phase II clinical trial for Chagas disease in Spain, led by Dr Israel Molina at the Hospital Val d'Hebron, Barcelona. If successful, it could be one of the first in a new line of treatment options in 40 years.

\section{No options, few choices}

Chagas disease desperately needs more treatment options. Benznidazole and nifurtimox were introduced $>40$ years ago, but have failed to control the disease as both appear to have limited efficacy for treating the chronic phase of infection (which is the most common presentation), require long treatment periods (60 days for benznidazole and up to 90 days for nifurtimox), and have potential side effects including skin rashes, nausea, and kidney and liver failure. Nifurtimox can also cause seizures and other nervous-system disorders. Moreover, many poor rural communities in endemic countries have little health-care infrastructure or support for patients to complete their treatment, which both reduces drug effectiveness and encourages drug resistance. "All these things mean that we must find
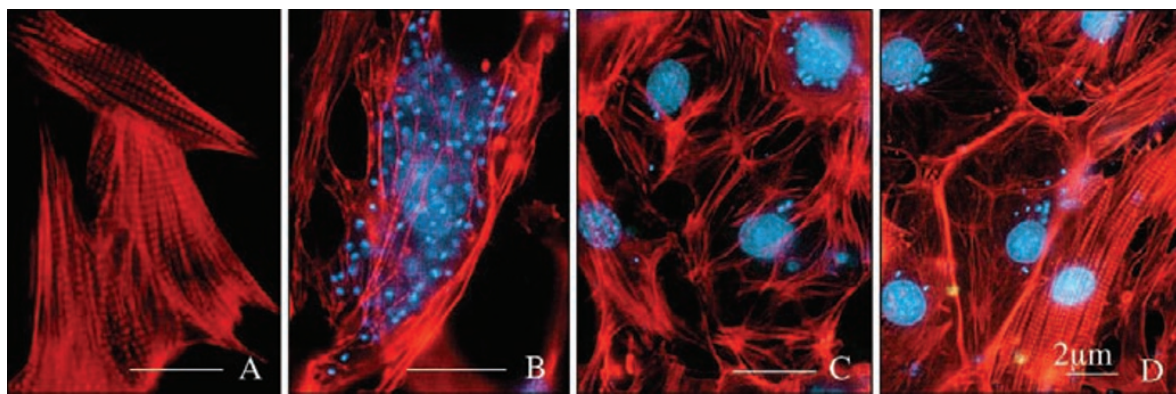

Myofibrils in uninfected cardiomyocytes (A), Trypanosoma cruzi-infected cardiomyocytes (B) and after posaconazole treatment (C, D). Reprinted with permission from ref. 14. another treatment for Chagas disease," says Maria de Nazare Soiero, who is head of the Cellular Biology Laboratory at the Oswaldo Cruz Foundation in Rio de Janeiro, Brazil.

Yet research into new therapies stalled towards the end of the twentieth century, partly because of a lack of government commitment to drug development in many Latin American countries, and partly because the (largely Western) pharmaceutical industry saw little financial incentive in treating tropical diseases.

The problem is not only money but also a lack of adequate infrastructure to support clinical trials in endemic countries, an absence of reliable techniques for diagnosis and monitoring of treatment, and little coordination between basic research and later drug development. The field has had to rely on small, non-randomized clinical trials, which are often only case studies, and the efforts of dedicated but under-funded individual researchers. Multicentre, randomized, placebo-controlled trials, on the scale of those performed in developed countries, require teams of health workers in endemic areas to diagnose and recruit volunteers, and extensive laboratory facilities for testing blood and other samples.

Another problem is measuring drug effectiveness. It is difficult to demonstrate cure in patients with T. cruzi infection using blood smears and standard microscopy, particularly in chronic disease patients in whom the parasites reside mostly in the gut, heart and other deep tissues. Traditional serological tests that detect antibodies against the parasite are poor indicators of cure: even after the parasite is eliminated, antibodies can persist for another 10 years before a person tests 'sero-negative'. "This is a problem for drug development because no company is going to wait 10 years," says Urbina. There is also a lack of standardized test kits and protocols with which to generate comparable results. Blood PCR tests are very sensitive, and are currently used in HIV and malaria, yet are only now being introduced for Chagas disease. "We are introducing PCR and trying to get it into clinical practice, but scaling up [production of test kits] is necessary 
by industry," says Sergio Sosa-Estani, who is a physician and epidemiologist at the National Centre for Research in Endemic Disease and the Ministry for Health, Argentina. However, levels of circulating parasites in chronic Chagas disease are frequently below the detection limit of even the most sensitive PCR methods. Thus, PCR cannot be used to verify cure but rather therapeutic failure (a positive test after treatment).

Prospects are improving, however. Following the example of public-private partnerships, such as the Medicines for Malaria Venture, the non-profit Drugs for Neglected Diseases Initiative (DNDi) was established in 2003 to act as a virtual pharmaceutical research and development (R\&D) organization: linking teams around the world and shepherding the most promising candidates through the drug pipeline. This involves basic science, the expensive and complex later stages of drug development, and even legal and technical expertise, freeing the field from dependency on the traditional pharmaceutical industry and serving as a vehicle for attracting new funding for R\&D. Key to the process is the DNDi's industrial approach whereby productivity is not measured just by publication of results, and drug-like molecules can be quickly abandoned if they fail to show satisfactory results.

\section{Practical advances}

The easiest way to improve the short-term outlook for Chagas disease is by modifying the already approved drugs. Benznidazole and nifurtimox seemingly work well in the acute and early chronic phases of infection, but there is no paediatric formulation; tablets containing adult doses have to be cut up, which can be inaccurate if not properly managed. In Barcelona, where $\sim 500$ babies each year are born with T. cruzi infection, doctors have achieved a $100 \%$ cure rate, according to Pinazo, and there has been no incidence of drug resistance ${ }^{2}$. In endemic countries, in comparison, Médecins San Frontières has reported cure rates in children and young adults as low as $5.4 \%$ or even $0 \%{ }^{3}$. A primary objective, therefore, is to create paediatric formulations. The Brazilian stateowned Pharmaceutical Laboratory of Pernambuco (LAFEPE) is in the process of creating a dispersible tablet containing a paediatric dose of benznidazole, which Shing Chang, R\&D director at the DNDi, expects to be available by the end of 2010. In Argentina, a liquid-based version is in development, says Sosa-Estani.

There is also a large, multicentre, randomized trial underway, the BENznidazole Evaluation for Interrupting Trypanosomiasis (BENEFIT) trial, to see whether this drug can reduce the severity of cardiac symptoms (and

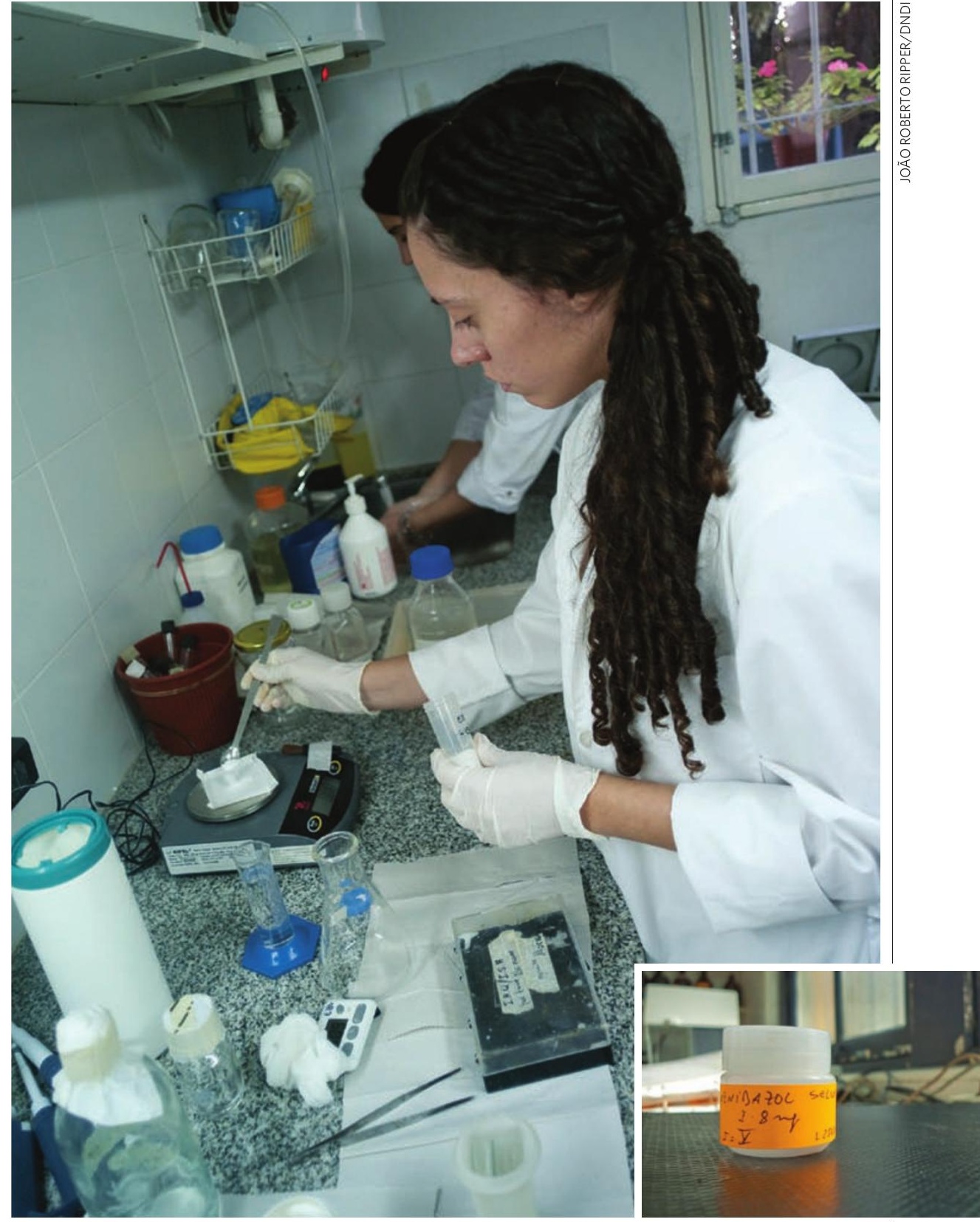

A pharmacist prepares a paediatric dose of benznidazole by hand in the Hospital de Niños, Argentina.

death) in chronically infected patients ${ }^{4}$. The trial focuses on patients who have already begun to show early signs of mild heart problems, thus avoiding following chronic yet asymptomatic patients, who might never develop complications, for 20 or 30 years. "The field has progressed slowly [partly because] you can test against the acute phase but when you get a chronic infection how can you measure effectiveness or cure? It's a real sticking point", says Simon Croft who is at the London School of Hygiene and Tropical Medicine in the United Kingdom, and previously spearheaded the DNDi's efforts at drug R\&D.

Also high on the agenda are drug combinations, which are commonly used to treat other diseases, such as HIV and malaria, but have not yet been tested in Chagas disease. Potential drug synergies could allow lower doses of each drug to be used, thereby reducing costs and side effects. Researchers at the University of Ouro Preto in Brazil are exploring these combinations, supported by the DNDi.

A different strategy is to explore drugs already approved for other conditions. Posaconazole is just one of several azole-based antifungals that could be effective for Chagas disease, but is not without its drawbacks. As Urbina notes, "Posaconazole is an amazing drug: a powerful compound and very safe. It's more potent than any other agent against T. cruzi but expensive and difficult to synthesize. A course of treatment would cost thousands of dollars in the USA". Indeed, treatment of the Barcelona patient cost the hospital around $€ 8,000$, according to Pinazo.

Thus, even if approved, posaconazole would not be affordable for the majority of patients in endemic countries. "Posaconazole at its current price is not the solution, but it could 


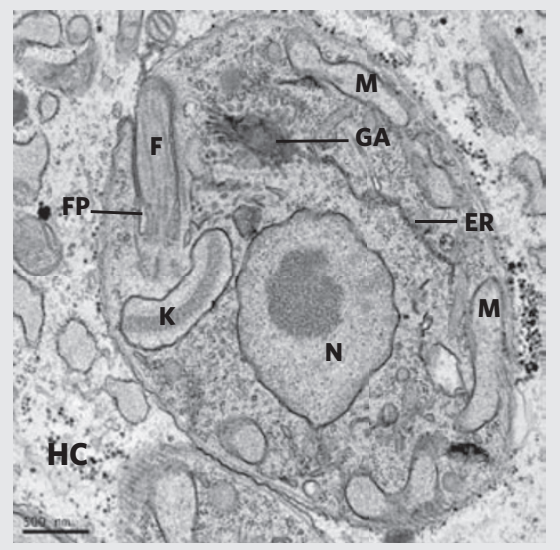

$\mathrm{HC}=$ Host cell; $\mathrm{F}=$ Flagellum; $\mathrm{ER}=$ Endoplasmic reticulum; $\mathrm{GA}=$ Golgi apparatus; $\mathrm{FP}=$ Flagellar pocket $\mathrm{M}=$ Mitocondria $\mathrm{K}=$ Kinetoplast (contained within the mitochondrion).

\section{Electron micrograph of Trypanosoma cruzi in} amastigote stage, in a mammalian host cell.

be the compound that opens the door for a new type of treatment. After posaconazole has been shown to be safe and effective in humans there could be a lot of compounds in the same class but less expensive", says Urbina. Other azole derivatives showing promise include E12-24 and Tak-187 (Table 1). The DNDi, in partnership with Eisai, plans to initiate a phase II trial of E12-24 in Chagas patients in Bolivia by the end of 2010. Meanwhile, amiodarone and dronedarone, which are used routinely to treat heart arrhythmia, are also able to kill T. cruzi selectively in cell culture and animal models, and anecdotal reports show they can also reduce parasite load in infected patients.

\section{The long-term view}

Combining or adapting existing approved drugs might yield quick results in the short term, but new treatments are needed to feed the $\mathrm{R} \& \mathrm{D}$ pipeline. One candidate is $\mathrm{K} 777$, which is the first drug to target the major cysteine protease of T. cruzi, cruzipain ${ }^{5}$. Following years in development with different researchers, K777 is finally poised to go into a phase I safety trial, after refinement and extensive testing by Jim McKerrow's team at the Sandler Center for Drug Discovery in San Francisco in the United States. McKerrow believes that the chances for K777 are good. "There are other cysteine protease inhibitors in development, but K777 is the most extensively characterized in efficacy and safety studies in rodents, dogs and primates".

Unlike most research institutions that lack the capacity to optimize lead candidates and take them into clinical trials, the Sandler Center has an unusual structure as a "series of labs that look like a company", according to McKerrow. Like the DNDi's virtual R\&D programme, the Sandler Center is more akin to the pharmaceutical industry than academia, and different teams are able to identify and test new drug candidates, improve their biochemical and pharmacokinetic properties, and file an investigational new drug (IND) application with the Food and Drug Administration (FDA). K777 has passed a pre-IND meeting with the FDA, and McKerrow's team, now in collaboration with the DNDi, is waiting for funds from the National Institutes of Health for good manufacturing practice manufacture and launch of the first clinical study.
There are other potential enzyme targets on T. cruzi, yet the difficulty of establishing reliable and reproducible in vitro assays has hampered efforts to screen new compounds. It can take $>1$ month to create and run an assay - generating sufficient numbers of parasites, getting them to the infectious phase of their life cycle, and then testing compounds over a range of different times and concentrations. High-throughput whole-cell assays improve the speed at which new compounds can be assessed (Box 1). To help standardize the screening process and allow comparisons among researchers, Soeiro is working on recommendations ${ }^{6}$. "The lack of well established protocols regarding the different aspects of the biology of parasites has impaired the finding of novel compounds over the last 30 years", she says.

Soeiro's own research shows that the arylimidamine compound B766 appears "very effective" in vitro and in vivo against a panel of field strains. Unlike benznidazole, B766 is active at temperatures as low as $4{ }^{\circ} \mathrm{C}$, making it suitable for the treatment of donated blood packs suspected of being infected with T. cruzi. This is potentially the first new blood-pack treatment for 80 years - since the introduction of gentian violet, which has the downside of turning blood blue, and sometimes causing vomiting and gastrointestinal alteration.

\section{Going upstream}

In addition to the known targets of T. cruzi, there are hundreds of genes of unknown

Table 1 | Clinical pipeline for Chagas disease

\begin{tabular}{|c|c|c|c|c|}
\hline Drug name/company & Current use & $\begin{array}{l}\text { Potential use in } \\
\text { Chagas disease }\end{array}$ & Target/mechanism & Stage of testing \\
\hline $\begin{array}{l}\text { Benznidazole } \\
\text { (LAFEPE) }\end{array}$ & $\begin{array}{l}\text { Routine clinical use for } \\
\text { acute and early chronic } \\
\text { Chagas disease }\end{array}$ & $\begin{array}{l}\text { Prevention } \\
\text { of chronic } \\
\text { cardiomyopathy }\end{array}$ & $\begin{array}{l}\text { Covalent modification of } \\
\text { macromolecules; DNA damage }\end{array}$ & $\begin{array}{l}\text { Phase III randomized, placebo-controlled, } \\
\text { multicentre trial for chronic Chagas } \\
\text { cardiomyopathy (BENEFIT) }\end{array}$ \\
\hline $\begin{array}{l}\text { Posaconazole } \\
\text { (Merck \& Co., Inc.) }\end{array}$ & Anti-fungal & $\begin{array}{l}\text { All stages } \\
\text { of disease }\end{array}$ & $\begin{array}{l}\text { CYP51 in the biosynthetic pathway for } \\
\text { the lipid ergosterol }\end{array}$ & $\begin{array}{l}\text { Phase II trial planned in Spain (I. Molina, } \\
\text { personal communication); trial plans also } \\
\text { announced by Schering Plough (prior to merger } \\
\text { with Merck \& Co., Inc.) })^{9,10}\end{array}$ \\
\hline $\begin{array}{l}\text { E12-24 } \\
\text { (Eisai, Japan) }\end{array}$ & $\begin{array}{l}\text { Pro-drug of anti-fungal } \\
\text { ravuconazole, not yet } \\
\text { approved }\end{array}$ & $\begin{array}{l}\text { All stages } \\
\text { of disease }\end{array}$ & CYP51 & $\begin{array}{l}\text { Phase I trial completed; phase II trial in Bolivia } \\
\text { planned (with potential for extension to Spain; } \\
\text { DNDi) }\end{array}$ \\
\hline $\begin{array}{l}\text { Tak-187 } \\
\text { (Takeda, Japan) }\end{array}$ & $\begin{array}{l}\text { Anti-fungal, not yet } \\
\text { approved }\end{array}$ & $\begin{array}{l}\text { All stages } \\
\text { of disease }\end{array}$ & CYP51 & Phase I trial completed ${ }^{9}$ \\
\hline $\begin{array}{l}\text { Amiodarone } \\
\text { (off-patent) and } \\
\text { dronedarone } \\
\text { (Sanofi-aventis) }\end{array}$ & Heart arrhythmia & Chronic stage & $\begin{array}{l}\text { Disruption of parasite calcium } \\
\text { homeostasis and inhibition of } \\
\text { ergosterol biosynthesis }\end{array}$ & $\begin{array}{l}\text { Most frequently used anti-arrhythmic drug in } \\
\text { Chagas disease patients }{ }^{12} \text {; anti-T. cruzi activity } \\
\text { in vitro and in vivo } 0^{12} \text {; anecdotal anti-parasitic } \\
\text { activity in individual patients }{ }^{13}\end{array}$ \\
\hline $\begin{array}{l}\text { K777 (Sandler } \\
\text { Center for Drug } \\
\text { Discovery) }\end{array}$ & Not yet approved & $\begin{array}{l}\text { Novel use } \\
\text { against Chagas } \\
\text { disease }\end{array}$ & Cruzipain & In preparation for phase I safety trial ${ }^{5}$ \\
\hline
\end{tabular}

BENEFIT, BENznidazole Evaluation For Interrupting Trypanosomiasis; CYP51, sterol 14 a-demethylase; DNDi, Drugs for Neglected Diseases Initiative. 


\section{Box 1 | Speeding up drug screening}

Whole-cell assays allow new drugs to be screened for efficacy without knowing the molecular targets. High-throughput screens (HTSs) are vital in the quest for new compounds, but until recently have been lacking for Chagas disease.

At the Swiss Tropical and Public Health Institute, Reto Brun provides a 'gold standard' screening centre for protozoan parasites for the World Health Organization (WHO)-Special Programme for Research and Training in Tropical Diseases (TDR) and the Drugs for Neglected Diseases Initiative (DNDi), as well as the Gatesfunded Consortium for Parasitic Drug Development (CPDD). His in vitro system involves the cultivation of Trypanosoma cruziinfected rat myoblasts in 96-well microtitre plates, using genetically modified parasites that express a bacterial enzyme that can be quantified by photometry. This allows the screening of up to 1,000 compounds a week.

At the Sandler Center, husbandand-wife team Juan Engel and Patricia Doyle have created a medium-to-high-throughput system using a robotic liquid handler dispensing into 96-well microtitre plates. This uses an automated microscope to detect DNA-stained parasite kinetoplasts in primary cell cultures from skin, muscle, liver and macrophages, and quantifies the number of $T$. cruzi per host cell. Screening capacity has risen from 100 compounds a month to 1,000 compounds a week in whole-cell assays, or tens of thousands a week in enzyme biochemical assays.

Fred Buckner at the University of Washington Seattle in the United States has developed an HTS based on 384-well plates and recombinant $T$. cruzi expressing fluorescent $\beta$-galactosidase: "We've gone from an era where you could test a handful of compounds in a week to [one where it is possible to test] 250,000 in a few weeks. It's helping everybody who's interested in screening drugs - a much needed tool." He has shared the system with laboratories in Brazil, Argentina, Panama, the United States and Europe.

One of the fastest HTS systems belongs to Lucio Freitas-Junior

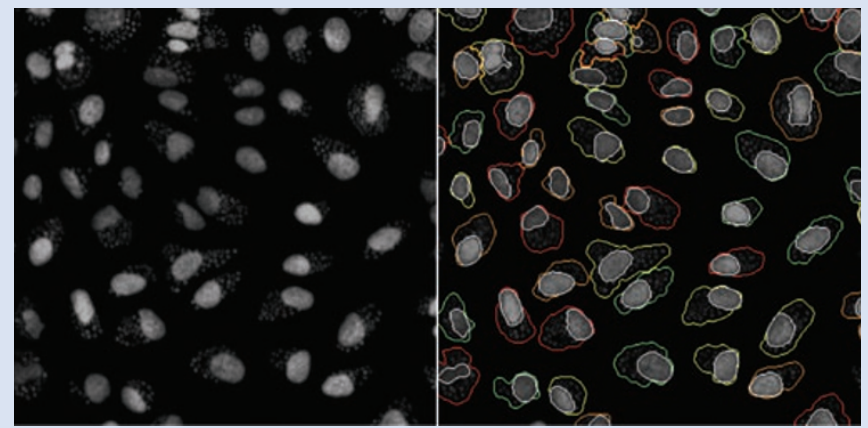

Images of an osteoblast human cell line infected with Trypanosoma cruzi before (left) and after (right) software detection of cell boundaries.

at the Institute Pasteur in Korea: a 384-well cell-culture system that combines an automated confocal microscope with an image analyser (pictured) to screen up to 30,000 compounds a week. Through DNA staining of wild-type rather than genetically modified T. cruzi, the system's software can count the number of parasites per cell and the number of cells per well, measure the size and shape of each cell to give a read-out of viability and morphological change owing to parasite infection, and determine the effects of the would-be inhibitors. A second step selects compounds that interfere with replication of parasite kinetoplast DNA (which provides a specific set of targets that are relatively similar among
T. cruzi, Trypanosoma brucei and Leishmania). Freitas-Junior and colleagues are now screening a Pfizer library of 150,000 compounds for leads against Leishmania and T. cruzi with a commission from the DNDi.

The HTS technology "has not been applied broadly in support of drug discovery for neglected diseases, so it presents a great opportunity to evaluate a large number of compounds to generate starting materials for further analysis", says Solomon Nwaka of the WHO-TDR. Nonetheless, Nwaka is under no illusions about the difficulty of moving to the next state. "Just because you have a million compounds available to screen, doesn't mean you will get a new drug. HTS just gets you to the next step". function (see The promise of T. cruzi genomics on page S16). As such, genomics is fuelling the identification of many potential drug targets, which need to be prioritized. Much of this effort is carried out under the auspices of the Special Programme for Research and Training in Tropical Diseases (TDR) Targets network, using the TDR Targets database (www.tdrtargets.org). "Before it was down to individual investigators to recommend their pet targets for screening. Now we have a set of criteria, that can be used to weight and prioritize drug targets", says Solomon Nwaka, who is head of drug discovery and innovation research for infectious tropical diseases at the World Health Organization (WHO)-TDR. Target-based drug discovery is high risk and the attrition rate is high, according to Nwaka, who fears that the current level of investment for drug discovery for neglected diseases is weak.

The TDR Targets network will soon be proposing a prioritized list of T. cruzi targets based on a set of weighted criteria, which could support screening against a collection of drug-like compounds. "If we're successful in getting an inhibitor of a validated target to kill whole parasites then we have a starting point for further analysis," says Nwaka. This means that, despite some ongoing screening activities, it could still take years or decades for new drugs to emerge from the Chagas disease $R \& D$ pipeline.

What could stall the field yet again is lack of investment. According to the Global Funding of Innovation for Neglected Diseases (G-FINDER) report ${ }^{7}$, the current funding for Chagas disease is a "meagre amount" and "highly unlikely to result in the necessary new Chagas disease products (diagnostics, drugs or vaccines) within the next half a century". Although that might make the field sound worse than it is, says Urbina: "The G-FINDER report only looks at formal investment [...] Posaconazole and other anti-fungals such as ravuconazole or Tak-187 that have been shown to be active against T. cruzi are not the result of formal industrial R\&D programmes [for Chagas disease] but rather from work carried out at public, nonprofit, research institutions in collaboration with pharmaceutical companies, and yet they are entering clinical trials." Success stories, such as the cure of the Barcelona patient with posaconazole, show that there is hope for new drugs against Chagas disease - and, moreover, that it is worth major and formal investment. With the unprecedented level of cooperation between different laboratories worldwide, every penny will be better spent than before.

Julie Clayton
Pinazo, M. J. et al. Am. J. Trop. Med. Hyg. 82, 583-587 (2010).

2. Muñoz, J. et al. Clin. Infect. Dis. 48, 1736-1740 (2009).

3. Yun, O. et al. PloS Negl. Trop. Dis. 3, 1-7 (2009).

4. Marin-Neto, J. A. et al. Am. Heart J. 156, 37-43 (2008).

5. Doyle, P. S. et al. Antimicrob. Agents. Chemother. 51, 3932-3939 (2007)

6. Romanha, A. J. et al. Mem. Inst. Oswaldo Cruz 105 233-238 (2010)

7. G-FINDER: Global Funding of Innovation for Neglected Diseases. The George Institute for International Health <http://www.thegeorgeinstitute.org/research/healthpolicy/current-projects/g-find-global-funding-ofinnovation-for-neglected-diseases.cfm $>$ (2007).

8. The BENEFIT Trial: Evaluation of the Use of an Antiparasital Drug (Benznidazole) in the Treatment of Chronic Chagas' Disease. ClinicalTrials.gov < http://www. clinicaltrials.gov/show/NCT00123916> (2005).

9. Urbina, J. A. Mem. Inst. Oswaldo Cruz 104 (suppl. 1), 311-318 (2009).

10.Schering-Plough R\&D for Chagas Disease. International Federation of Pharmaceutical Manufacturers and Associations. Health Partnerships: Developing World 2009 <http://www.ifpma.org/index.php?id=2169> (2009).

11. Eisai and DNDi Enter into a Collaboration and License Agreement To Develop a New Drug for Chagas Disease. DNDi Press Releases 2009 <http://www.dndi.org/pressreleases/532-eisai-and-dndi-enter-into-a-collaboration. html> (2009).

12. Benaim, G. et al. J. Med. Chem. 49, 892-899 (2006).

13. Paniz-Mondolfi, A. E. et al. Chemotherapy 55, 228-233 (2009).

14. Silva, D. T. et al. Int. J. Antimicrob. Agents 27, 530-537 (2006). 